\title{
ARQUITECTURA NOSOCOMIAL EN LA CORUÑ̃A GÓTICA
}

\author{
Por \\ $M^{a}$ DOLORES BARRAL RIVADULLA
}

Arquitectura nosocomial u hospitalaria. Un campo dentro de la arquitectura civil que ha sido poco estudiada en el caso gallego durante el período medieval, sobre todo teniendo en cuenta que en nuestra región la proliferación de la misma estará favorecida por el Camino de Santiago. Y no sólo los hospitales vinculados al Camino sino también los hospitales fundados en villas, ciudades, burgos... todavía no han sido acometidos de una manera global. La gran cantidad de noticias que sobre fundaciones hospitalarias se guardan en nuestros archivos y los diversos trabajos que sobre los mismos han sido publicados no han logrado todavía ver la luz en un estudio en el que se relacionen su realidad histórica y arquitectónica. En este trabajo se presenta el análisis realizado a partir del ejemplo de la ciudad de La Coruña en los siglos del gótico y que pretende ser un anticipo de un estudio más global sobre este tipo concreto de inmuebles.

En primer lugar ha de centrarse la realidad de lo que supone una fundación hospitalaria durante los siglos medievales para después plantear el caso concreto de la arquitectura hospitalaria coruñesa ${ }^{1}$.

\footnotetext{
${ }^{1}$ Para el análisis de la concepción y significado de estas instituciones véanse, entre otros, los trabajos de: RUBIO VELA, Agustín: Pobreza, enfermedad y asistencia hospitalaria en la Valencia del siglo XV. Valencia, 1984; y LÓPEZ ALONSO, Carmen: La pobreza en la España Medieval. Madrid, 1986.
}

"CUADERNOS DE ESTUDIOS GALLEGOS", Tomo XLIII, Fascículo 108, Santiago 1996. 
El hospital medieval es concebido como un edificio para albergar indistintamente a tres tipo humanos: los enfermos, los pobres y los peregrinos. Lejos de la concepción moderna de hospital -edificio dedicado a la asistencia sanitaria- en la Edad Media éstos pueden ser definidos como lugar de acogida o refugio, entidades abiertas que beneficiarán a aquéllos que por condición física, económica, social o circunstancial necesitan de un espacio donde cobijarse y ser atendidos. Incluso llegará a confundirse el concepto de hospital con el de hospedaje, derivado de la estancia de peregrinos en los mismos.

Las fundaciones hospitalarias altomedievales en la península ibérica son muy puntuales y, en su mayoría, aparecen ligadas a un establecimiento eclesiástico. Sin embargo, a partir del siglo XII este tipo de instituciones aumentan en importancia al amparo de diversas circunstancias, como por ejemplo, la creciente trascendencia del Camino de Santiago que conducirá a monarcas, nobles, diversas órdenes militares y monásticas, e incluso a particulares a establecer una infraestructura básica de asistencia para peregrinos en los principales núcleos poblaciones del Camino ${ }^{2}$.

Sin embargo, ésta no será la única razón del incremento de estas fundaciones durante el Bajomedievo sino que además han de considerarse otros motivos relacionados directamente con el nacimiento de un nuevo sentimiento religioso ${ }^{3}$ y con el renacimiento urbano ${ }^{4}$.

En consecuencia, tal vez se imponga en este momento realizar un breve balance de los nuevos valores y cambios introducidos en la mentalidad laica y al mismo tiempo en la propia religiosidad de las gentes que han comenzado a asociar la salvación del alma con la realización de obras de caridad. Pero, sobre todo, y por influencia de las órdenes mendicantes,

\footnotetext{
${ }^{2}$ Aunque esta labor había comenzado en torno al siglo X será a partir del siglo XII cuando esta tendencia experimente un mayor auge. Según Vázquez de Parga, Lacarra y Uria Riu, el primer hospital ligado al Camino será el que consta en una donación de Ramiro II, por la que se concede una iglesia dedicada a San Andrés al monasterio de Sahagún (datada en 7 de abril de 945). Entre esta fecha y hasta el siglo XII los mismos autores mencionan únicamente cinco hospitales: Sahagún, Villa Vascones, Arconada, Nájera y Santo Domingo de la Calzada. VÁZQUEZ de PARGA, Luis, LACARRA, José María y URIA RIU, Juan: Las peregrinaciones a Santiago de Compostela. T. II, Pamplona, 1993, (reed.), pp. 292-295.

${ }^{3}$ LÓPEZ ALONSO, op. cit., p. 259.

${ }^{4}$ IDEM, p. 427.
}

"CUADERNOS DE ESTUdIOS GALLEGOS", Tomo XLIII, Fascículo 108, Santiago 1996. 
una positiva valoración del ocio y de aquellas virtudes que pueden dignificar al individuo en sus obras y en la trascendencia de las mismas. El hombre ha asumido su temporalidad ${ }^{5} \mathrm{y}$, aunque la alegría de vivir toma valores de protagonismo, el miedo a condenarse - aspecto tan claramente expresado en los certificados de últimas voluntades- es la otra constante. Como respuesta o solución a este miedo había aparecido el tercer lugar, que otorgaba al alma la posibilidad de salvarse a través de las buenas obras. Nace, consecuentemente, la denominada por Chiffoleau «contabilidad del más allá» ${ }^{6}$. Gracias a ésta el fiel intentará la salvación de su alma por medio de la realización de buenas obras, las mandas destinadas a hospitales descritas en los testamentos, e incluso la fundación en vida de éstos, se convierten en cuentas de cargo que asegurarán que la balanza, en su platillo de las obras dignificantes, pese un poco más. Aunque también, ha de señalarse, como apunta Rubio Vela, que, en muchos casos, la fundación de hospitales materializa la pretensión de un personaje de buscar cierta inmortalidad, el ser recordado por los vivos tras la muerte ${ }^{7}$. Es, en definitiva, un reflejo de la lucha contra la damnatio memoriae que tanto intimidaba al poderoso desde tiempo de los romanos.

El segundo factor decisivo que influirá en el incremento de las fundaciones hospitalarias será, como se ha mencionado, el desarrollo urbano. La aparición de la necesidad de dotar a las ciudades de una infraestructura que atienda a todos los componentes de la sociedad civil dará lugar a la fundación de de hospitales tanto por parte de los municipios, particulares o cofradías. Su creación será, en principio, la respuesta urbana a la marginación y a la pobreza. Y se ha remarcado la idea de «en principio» por que estas fundaciones pasarán a convertirse en muchos casos y en los años finales del medievo, en un elemento de estabilidad social. En un momento en que el pobre ha pasado de ser objetivo de caridad a ser sujeto vagabundo del cual la sociedad ha de defenderse ${ }^{8}$.

${ }^{5}$ Es la idea de la muerte propia. ARIES, Philippe: La muerte en Occidente. Barcelona, 1982 , p. 41.

${ }^{6}$ CHIFFOLEAU, Jacques: La comptabilité de l'au-delá. Les hommes, la mort et la religion dans la region d'Avignon à la fin du Moyen Age (vers. 1320 - vers. 1480). Rome, 1980, p. 91.

${ }^{7}$ RUBIO VELA, op. cit., p. 27.

${ }^{8}$ Idem, op. cit., p. 18.

"CUADERNOS DE ESTUDIOS GALLEGOS", Tomo XLIII, Fascículo 108, Santiago 1996. 
Todos los factores y circunstancias mencionadas hasta el momento unificadas dan lugar a un nuevo modelo hospitalario, siendo la característica fundamental de estas nuevas instituciones el que, frente al tipo de hospital de los siglos precedentes ligado fundamentalmente a instituciones monásticas, son fundaciones de carácter secular. Tanto particulares como concejos o cofradías de las ciudades, villas y burgos serán los nuevos protagonistas encargados de poner en funcionamiento y administración de estas instituciones.

Sin entrar en pormenores sobre el funcionamiento interno y administración de los hospitales, que no competen a este análisis y que únicamente se irán abordando de manera puntual y en aquellas circunstancias en que la documentación aluda a los mismos, antes de entrar en el estudio de las fundaciones coruñesas, ha de hacerse una breve mención a un tipo de hospitales que, frente a la falta de especialización genérica que se observa entre los mismos durante el período medieval, sí aparecen dedicados al tratamiento concreto de una enfermedad: la lepra.

Las leproserías pueden considerarse como los primeros hospitales especializados, teniendo en cuenta que esta especialización nunca debe ser considerada desde un punto de vista sanitario sino desde un concepto de reclusión y de aislamiento especial.

La fundación de una leprosería es la consecuencia directa de una sociedad que margina a los que padecen dicha enfermedad, no tanto por el carácter contagioso de la misma sino por su manifestación externa ${ }^{9}$. Como afirma N. Gugliemi:

«quienes la sufren no sólo ven comprometida su salud sino también su posición dentro de la sociedad que les rechaza, los confina, los limita» ${ }^{10}$

\footnotetext{
${ }^{9}$ Véase el concepto de esta enfermedad en CONTRERAS, Antonio y ROSELLÓ, Ramón: La asistencia pública a los leprosos en Mallorca (Siglos XIV al XIX). Mallorca, 1980, p. 11.

${ }^{10}$ GUGLIEMI, Nilda: «Modos de marginalidad en la Edad Media: extranjería, pobreza, enfermedad» en Anales de Historia Antigua y Medieval. 16(1971), pp. 7-187 (para nota p. 68).
}

"CUADERNOS DE ESTUDIOS GALLEGOS", Tomo XLIII, Fascículo 108, Santiago 1996 
Esta marginalidad del enfermo leproso también atañe a la mujer, a la que se considera como candidata idónea para la atención al enfermo ya que, conforme a la maldición bíblica, se la supone con condiciones especiales para enfrentarse al mal, a lo impuro.

El desconocimiento científico del carácter real de la enfermedad hacen que en la sociedad medieval cobre valor el texto del Levítico donde se dice:

«cuando uno tenga en la piel de su carne tumor, erupción o mancha blancuzca brillante, y se forme en la piel de su carne como una llaga de lepra, será llevado al sacerdote Aarón o a uno de sus hijos, los sacerdotes. El sacerdote examinará la llaga en la piel de la carne ; si el pelo en la llaga se le ha vuelto blanco, y la llaga parece más hundida que la piel de su carne, es llaga de lepra; cuando el sacerdote lo haya comprobado, le declarará impuro (...) El afectado por la Lepra llevará los vestidos rasgados y se desgreñará la cabeza, se cubrirá hasta el bigote e irá gritando: « ¡Impuro, impuro!». Todo el tiempo que dure la llaga quedará impuro. Es impuro y habitará sólo; fuera del campamento tendrá su morada»

(Levítico, cap. XIII).

Esta descripción bíblica de la enfermedad y las características de su tratamiento parecen condicionar el emplazamiento de las leproserías: lejos de las ciudades y sus arrabales e incluso, llevó a la identificación de los enfermos por medio de distintas señas, como las «tablillas de San Lázaro» ${ }^{11}$ por medio de las que éste anuncia su paso a aquellos que podrían cruzarse en el camino.

Todas estas características pueden ejemplificarse en el caso coruñés donde el lazareto, bajo la advocación de Santa Lucía, está ubicado en las afueras de la ciudad, lejos del arrabal de la Pescadería, en la aldea de su mismo nombre.

Sobre su fundación poco puede aventurarse, Vedía Goossens establece que ésta podría ser del siglo XIV ${ }^{12}$. Circunstancia que parecen confirmar los documentos, aunque queda abierta la posibilidad de que su fun-

\footnotetext{
${ }^{11}$ CONTRERAS y ROSELLÓ, op. cit., p. 11.

${ }^{12}$ VEDÍA GOOSSENS, Enrique de: Historia y descripción de la ciudad de La Coruña. Ed. Facsímil de la de 1845, La Coruña, 1975, pp. 253-254.
}

"CUADERNOS DE ESTUDIOS GALLEGOS", Tomo XLIII, Fascículo 108, Santiago 1996. 
dación fuese incluso anterior a este siglo, pudiendo ser contemporánea a la fundación de la villa, en el año 1208, momento en que parece que se establece toda una infraestructura urbana en la que de alguna manera debía ser contemplada la fundación de una institución de este tipo. Sin embargo, esta última idea sólo debe quedar expresada a modo de hipótesis ya que la documentación no permite confirmarla.

Pocos son los datos que sobre el funcionamiento de esta entidad se conocen. En primer lugar no sabemos cómo se realizaba, o si se efectuaba un reconocimiento médico previo al ingreso del enfermo en la institución. La investigación y la solicitud del reconocimiento médico de un enfermo antes del ingreso en el lazareto no se observan en el caso castellano, sin embargo, sí en el caso mallorquín, tarea que estaba encargada al instigador dels massells. Se ha recogido aquí en qué consistía dicha práctica, por considerarla uno de los efectos más evidentes del carácter marginal que llevaba implícito la enfermedad:

«Los individuos sospechosos del padecimiento tenían que denunciarse a las autoridades. Se les examinaba y como el diagnóstico podía ser de consecuencias terribles (...) el examen se efectuaba en circunstancias especialmente solemnes (...) en Italia frecuentemente agregaban a un abogado al grupo de diagnóstico (...) Previamente al reconocimiento de los médicos y el paciente prestaban juramento de conducirse rectamente y de no falsear los elementos de juicio. El abogado exhortaba a los médicos a proceder con gran cuidado y recordar bien los síntomas de la lepra tras el reconocimiento y diagnóstico positivo de lepra, en algunos países europeos se celebraba incluso una ceremonia de ingreso» ${ }^{13}$

También desconocemos para el caso coruñés quienes eran los que asistían a los enfermos. A este respecto puede suponerse que, como establecía el canon 23 del concilio de Letrán, fuesen religiosos los encargados de tal institución ${ }^{14}$. Velo Pensado en su estudio sobre la vida municipal del siglo XVI aventura la posibilidad de que en este caso fuesen religio-

\footnotetext{
${ }^{13}$ CONTRERAS y ROSELLÓ, op. cit, pp. 25-26.

${ }^{14}$ CAILLE, Jacqueline: Hôpitaux et charite publique à Narbonne au Moyen Age. Toulouse, 1978, p. 33.
}

"CUADERNOS DE ESTUdIOS GALLEGOS", Tomo XLIII, Fascículo 108, Santiago 1996. 
sas de la Orden de San Lázaro las encargadas de la leprosería ${ }^{15}$. En cualquier caso, sobre todo a la luz de las múltiples representaciones miniadas que de esta época existen, es la mujer viuda la que junto a la religiosa cumple con las funciones de asepsia, alimentación e intendencia al necesitado, cabe pensar que fuesen mujeres las encargadas de tal función.

Parte del mantenimiento del lazareto coruñés se cubría con limosnas y donaciones procedentes de las mandas testamentarias. Por sistema casi todos los testamentos coruñes analizados hasta este momento recogen una donación para esta institución como si constituyera una cláusula consagrada en la que sólo varía la cantidad o el tipo de donación. Así, por vía de ejemplo, se menciona al hospital de Santa Lucia en el testamento de Fernán Martínez, clérigo de la iglesia de Santo Tomás, que en 1399 dona,

«a os lazarados que y see así os que han razon como aos que ha non han dous maravedis» ${ }^{16}$

Gonzalo Sánchez en 1446 en su testamento establece:

«Iten mando os lazerados de Santa Luzia seis maravedis a todos» ${ }^{17}$

Roi Xordo das Mariñas, regidor de la villa lega por su testamento de 1457 importantes bienes inmuebles:

«Iten mando a todos los lazerados e lazeradas de Santa Lucia de a cerca da dita cibdad os dous tercios do meu casal de jermana para todo senpre para que o ajan e coman todos así os que an razon como os que a non (...) Iten mando aos sobreditos lazarados todo o casal

${ }^{15}$ VELO PENSADO, Ismael: La vida municipal de A Coruña en el siglo XVI. Diputación Provincial de La Coruña, La Coruña, 1992, p. 335.

${ }^{16}$ Testamento del clérigo Fernán Martínez, otorgado en La Coruña a 30 de enero del año 1399. Documento transcrito en GONZÁLEZ GARCÉS, Miguel: Historia de La Coruña. La Edad Media. La Coruña, 1988, documento ${ }^{\circ} 53$.

${ }^{17}$ Traslado del testamento de Gonzalo Sánchez, vecino de La Coruña, realizado en 12 de agosto de 1446. Documento en Archivo de la Colegiata de Santa María del Campo (a partir de esta nota citado como ACSMC), pergamino $n^{\circ} .51$.

"CUADERNOS DE ESTUDIOS GALLEGOS", Tomo XLIII, Fascículo 108, Santiago 1996. 
que fue de Roi Cuchando, que jaz en la felegresia de secebre, para que o ajan y leben para senpre con los ditos tercios do dito casal del jermana e rroguen a deus por mi anima y de mis antecesores» ${ }^{18}$.

María Oanes Bocarela, en 1462, dona cuatro juegos de sábanas:

«Iten mando aos lazerados de Santa Lucia da cerca desta dita çibdade asy aos que han raçon commo a os que a nen han, a todos quatro savaas de cama» ${ }^{19}$.

En el testamento de Gonzalo Martínez de Vilela, clérigo de Santa María de Rutis deja

«os lazerados de Santa Luzia de acerqua desta dita çibdad da Crunna asy hos que han raçon commo a os que non han tres maravedis» ${ }^{20}$.

Pero, sin duda, una de las mandas más importantes que recibe el lazareto coruñés será la de Gonzalo da Mariña, vecino del arrabal de la Pescadería, quien en 1480 ordena que, una vez cumplidas sus honras, sus cumplidores saquen de sus bienes treinta mil maravedíes y

«de ellos los diez mil los den a los lazarados al año para siempre» $»^{21}$

En esta serie de mandas, y en general en todas las que se han registrado para el hospital de Santa Lucia, no aparece ninguna donación directamente dedicada a su fábrica o al mantenimiento del inmueble. Esta cir-

${ }^{18}$ Testamento firmado en La Coruña a 24 de diciembre de 1457. Transcrito por GONZÁLEZ GARCÉS, op. cit., documento $\mathrm{n}^{\circ} 75$.

${ }^{19}$ Codicilo testamentario de María Oanes Bocarela, otorgado en La Coruña a 16 de noviembre de 1462. Documento en Archivo de las Clarisas de La Coruña ( a partir de esta nota citado como ACC), pergamino $\mathrm{n}^{\circ} 10$.

${ }^{20}$ Testamento de Gonzalo Martínez de Vilela, clérigo de Santa María de Rutis, dado 7 de julio de 1465. Documento en ACSMC, pergamino $n^{\circ} 50$.

${ }^{21}$ «Su escritura es de 30 de Março de 1480 por ante Francisco Garcia de Tordesillas escribano» GRABÓO MOSCOSO, Agustín: Breve resumen cronologico de los principios que tuvo el muy grave y religioso convento de Santa Bárbara y sus progresos en lo espiritual y temporal con su elenco de inventario de todos los papeles tocantes a la hacienda. La Coruña, 1691, fol. 26 v.

"CUADERNOS DE ESTUDIOS GALLEGOS", Tomo XLIII, Fascículo 108, Santiago 1996. 
cunstancia podría indicar el carácter municipal de la institución, lo que conllevaría que el mantenimiento general del hospital corriese a cargo del concejo. Un documento que puede demostrar esta dependencia del lazareto es una carta del Papa Inocencio VIII quien, en 4 de abril del año 1488, ordena a los abades de Soandres, Bergondo y Mantevao que determinen sobre el gobierno del lazareto de Santa Lucia que regía y había fundado el ayuntamiento ${ }^{22}$ :

«Innocentius episcopus servuus servorum Dei. Dilectis filiis de Suandres et de Bregondo er de Montefero, compostellam diocesis, Apostolicam monasterionum Abbatibus. Salut et apostolicam bedictionem: Querelam dilectorum filiorum modernorum rectorum et universitatis hominum opidi de Cruna, compostellam diocesis, accepimus continentem quod haec olim tunc rectores dicti opidi et universitas predicti domum Sancte Lucie, extramuros eiusdem opido, pro habitatione pauperum morbo lepre laborantium per rectores dicti opidi pro tempore existentes regendam et gubernandam rite fundaverunt sen deputaverunt illamque a funationis huiusmodi et alias a tanto tempore cuius contrarii hominum memoria non existit tam ipsi moderna quam alii rectores eiusdem opidi qui pro tempore fuerunt successiva rexerunt et gubernaverunt pacifice et quiete, tamen Afonsus de Camargo laicus prefatediocesis falso asserens prefatos modernos rectores et universitatem quominus dictam domum regereet gubernare possint de facto impedire presumpsit hactenus et presunt ni rectorum et universitatis predictorum previdicam no modiam et gravamen quare pro parte ipsorum rectores et universitatis nobis fuit humiliter supplicatum ut sibi super hoc institute magisterio subvenire paterna diligentia. Quo tuta dusiretioni me per apostolica scripta mandamus quatinus notatisqui fuerunt enocruidi et auditis hincinde propositus quod instum fuerit apellatione remota decernatie facientes quod decrenentis per sensuram ecclesiasticam firmiter observarum testes autem qui fuerunt nominati si se gratia odio vel timore subtiacerunt censura simili apellatione cessante compellatus veritate testimonium

\footnotetext{
${ }^{22}$ Este documento depositado en Archivo Histórico Municipal de La Coruña ( a partir de esta nota será citado como AHMC), pergaminos $n^{\circ} 32$.
}

"CUADERNOS DE ESTUdIOS GALLEGOS", Tomo XLIII, Fascículo 108, Santiago 1996. 
prehibere quod si non omnes exequendis potueritis interesse duo aut vivis. Datum Rome apud Sanctum Petrum anno Incarnationis Dominice Pontificatus Anno Quinto. (Sello de plomo con la inscripción: INNOCENTIUS P.P. VIII)»

Se desconoce la disposición general de la leprosería coruñesa. Sin embargo, en el plano de la ciudad realizado por Juan Santáns y Tapia en 1639, bajo el epígrafe Santa Lucía aparecen una serie de casas presididas por una iglesia con torre, se podría confirmar, en el caso coruñés, la hipótesis de N. Gugliemi quien supone que las leproserías son, por lo general, un conjunto de construcciones sin una disposición especial, pero orientados los edificios principales hacia mediodía, para buscar los efectos saludables del sol. Aún más este pequeño núcleo constituirá, siguiendo a la citada autora, una entidad autosuficiente cercada por una extensión rural, cultivada por los propios enfermos ${ }^{23}$.

Volviendo de nuevo al análisis general de las instituciones hospitalarias coruñesas, y una vez abordado el caso del lazareto, ha de puntualizarse, en primer lugar, que en la actualidad no se ha localizado el acta de fundación de ninguna de estas instituciones. Sin embargo, será a través de algunos documentos, sobre todo testamentos, los que permitan establecer hipótesis que nos acerquen a la época de su constitución.

Los centros que, junto con el mencionado hospital de Santa Lucía, aparecen mencionados en el documentación coruñesa son el hospital de Santiago y de los Ángeles. Como caso aparte será estudiado el hospital de San Andrés ya que la época de su fundación no puede ser claramente delimitada a través de la documentación.

Rey Escariz, que fue el primero en estudiar la historia hospitalaria coruñesa, afirma que en tiempos medievales existía también hospital de San Antonio, cuya fundación atribuía a la cofradía de la Vera Cruz, de los mareantes de la ciudad. Esta institución estaría dedicada al tratamiento de enfermos contagiosos y por esta causa estaba situada en el islote de San Antón ${ }^{24}$. Sin embargo, a pesar de las afirmaciones de dicho autor,

\footnotetext{
${ }^{23}$ GUGLIELMI, op. cit., p. 72.

${ }^{24}$ REY ESCARIZ, Antonio Abelardo: «Hospitales de la gente del mar en La Coruña» en BRAG 3(1908-9), pp. 170-174 (para nota p. 171).
}

"CUADERNOS DE ESTUDIOS GALLEGOS", Tomo XLIII, Fascículo 108, Santiago 1996. 
quien incluso aventura la idea de que una vez construido el hospital de San Andrés por la misma cofradía el hospital de San Antón se convertiría en capilla al cuidado de la comunidad franciscana coruñesa ${ }^{25}$, no se han encontrado datos que avalen dicha teoría. Esta hipótesis la sigue más tarde Rodríguez Villasante quien reitera, sin aportar las consiguientes referencias documentales que, cuando en 1525 se decidió construir el castillo de San Antón para defensa del puerto coruñés, en la isla estaba instalado un hospital de «apestados del ergotismo grangrenoso fuego de San Antón» que había diezmado la población de navegantes en el siglo $\mathrm{XV}^{26}$.

Los otros dos hospitales, el de Santiago y el de los Ángeles parecen haber sido fundados en el siglo XV; el hospital de Santiago aparece mencionado por primera vez en la documentación estudiada en el testamento de Teresa Gómez quien en 1435 dona al hospital

«de /cabo\Santiago desta villa que feso Juan Ferreño una coçerre pequena et hun cabeçal et una colcha et hun par de savanas» ${ }^{27}$

En el testamento se indica la ubicación del hospital, cercano a la iglesia de Santiago, y el nombre del fundador del mismo, Juan Ferreño. Este personaje puede ser identificado, a través de la documentación coruñesa, como jurado del concejo ${ }^{28}$. El centro, hospital fundado probablemente para la asistencia de peregrinos, estaba administrado por un clérigo, posiblemente de la vecina iglesia parroquial de Santiago. Esta afirmación se basa en un pleito sostenido por Pedro Gómez, en los años del arzobispado de Alonso de Fonseca II (1460-1464), por la administración de dicho hospital. El texto a través del que se transmiten estos datos es el siguiente:

${ }^{25}$ IBIDEM

${ }^{26}$ RODRÍGUEZ-VILLASANTE PRIETO, Juan A.: Historia y tipología arquitectónica de las defensas de Galicia. Funcionalidad, forma y ejecución del diseño clasicista. Sada (La Coruña), 1984, p. 81.

${ }^{27}$ Testamento de Teresa Gómez, firmado el 6 de julio de 1430. Documento en AHMC, carpetas de Isabel Martínez Barbeito, s. $\mathrm{n}^{\circ}$.

${ }^{28}$ Sirva de ejemplo el foro firmado en 1428 por el que Juan Ferreño, jurado de La Coruña, afora a Aldara Núñez, viuda de Gonzalo de Folgar y a Juan Folgar su hijo, carpintero, vecinos de dicha villa, una de sus casas en la calle de las Culleradas. ACSMC, pergamino $n^{\circ} 9$.

"CUADERNOS DE ESTUDIOS GALLEGOS", Tomo XLIII, Fascículo 108, Santiago 1996. 
«Provision original del juez eclesiastico de la coruña hecha a Pedro Gomez, clerigo de la administracion de un ospital en la Coruña.

Citacion del arzobispo Fonseca (II) para que el clerigo comparezca personalmente.

Testimonio signado de los autos que pasaron sobre la posesion del dicho ospital de Santiago de La Coruña, y commo el clerigo renuncio al título que a el tenia el arzobispo» ${ }^{29}$.

Sobre el hospital de los Ángeles se han apuntado diversas cronologías, González Garcés sitúa su fundación entre fines del siglo XIV y comienzos del $X^{30}$, mientras que Martínez Murguía ${ }^{31}$ y Parrilla Hermida ${ }^{32}$ datan su origen a fines del siglo XV. Martínez Murguía basaba su afirmación en una carta que el monarca Enrique IV dirige al Papa solicitándole determinados privilegios para un hospital de La Coruña ${ }^{33}$. El original de dicho documento se conserva en el Archivo de Simancas ${ }^{34}$. Tras confrontar el original con la transcripción efectuada por Murguía, han tenido que realizarse determinadas correcciones. En la lectura presentada aquí se han omitido algunas líneas para mostrar únicamente sus puntos más importantes:

«... un mi natural que se llama Iohan de Santiago, vecino de la çibdat de la Crunna, aviendo respetto al serviçio de Nuestro Sennor propuso de fazer una capilla a onor de los Angeles en la dicha çibdat de la Crunna, la qual ha comenzado a fazer e tiene puesta en buen estado. E por mas serviçio de Nuestro Señor el entiende luego fazer açerca de la dicha capilla un ospital en que duerman e se acojan los pobres $e$ enfermos e a otras personas que quisieren venir a el. Para lo qual

\footnotetext{
${ }^{29}$ Este dato se ha obtenido gracias a la transcripción de parte de un catálogo de los papeles que pertenecieron al arzobispo Fonseca II, realizada por Mercedes Vázquez Bertomeu. Documento en Archivo Histórico Diocesano de Santiago (a partir de esta nota será citado como AHDS), serie catálogos leg. 501. (año 1501).

${ }^{30}$ GONZÁLEZ GARCÉS, op. cit., p. 394.

${ }^{31}$ MARTÍNEZ MURGUÍA, Manuel: Historia de Galicia. T. I, Bilbao, 1979, p. 331.

${ }^{32}$ PARRILLA HERMIDA, Miguel: «Historia del hospital militar de La Coruña. Un documento y un plano» en $C E G 9$ (1954), pp. 91-124 (para nota p. 91)

${ }^{33}$ MARTÍNEZ MURGUÍA, op. cit., p. 331 , nota ${ }^{\circ} 2$.

${ }^{34}$ AGS, secretaria de estado, legajo $1-1^{\circ}$, fol. 125.
}

"CUADERNOS DE ESTUDIOS GALLEGOS", Tomo XLIII, Fascículo 108, Santiago 1996. 
querria aver de vuestra santidad indulgencia para que todo aquel que moriere en el dicho ospital fuese absuelto a culpa e a pena e porque la dicha çibdat (...) es puerto de mar e de los principales de mis Reynos y sennorios e donde muchas personas estrangeras asi pobres como romeros e otras muchas personas ocurren de cada día (...) vuestra santidad diese indulgençia e algunos perdones a los que diesen alli sus limosnas (...) scripta (en blanco) de (en blanco) anno LXIIII»

Conforme a la lectura del documento se observan los siguientes datos; Juan de Santiago fue el fundador de una capilla bajo la advocación de los Ángeles, el mismo, en el año 1464, ante la idea de fundar un hospital para pobres anexo a dicha capilla solicitará al monarca, y éste a su vez al Papa, la concesión de determinadas indulgencias que favorezcan y ayuden al mantenimiento de dicha institución.

No se conoce cual fue la resolución papal pero lo cierto es que el hospital fue fundado y comenzó a funcionar de manos de Pedro López quien, en el año 1493, solicitará a los alcaldes mayores del reino de Galicia que le amparen en la posesión de dicha institución ya que el mismo lo había edificado y fundado:

«Pedro Lopes, vesino de la çibdad de La Corunna, (...) a grandes tempos que por ser merçed de Dios fiso, edefico un hospital en la pescaderia de la dicha çibdad para donde fuesen acogidos los pobres e pelegrinos que se llama el hospital de los Angeles que esta cabo el monesterio de Santo Domingo de la dicha çibdad» ${ }^{35}$.

De todos modos, y sin poder precisar más, en cuanto a los fundadores de dicha institución, es evidente que durante el siglo XVI el hospital está funcionando bajo la dirección del concejo de la ciudad, aunque según un documento de 1608 y que se recoge más adelante parece que tambíen la cofradía de los mareantes aparecía implicada en su mantenimiento. El hospital era refugio de pobres y peregrinos, los cuales para poder ingresar en el mismo deberían juntarse en la iglesia de Santiago donde se los inscribía, excluyéndose a quienes que no reuniesen las condiciones mínimas

${ }^{35}$ Valladolid, 24 de noviembre de 1493. Documento en AGS, sello 1493, fol. 186.

"CUADERNOS DE ESTUDIOS GALLEGOS", Tomo XLIII, Fascículo 108, Santiago 1996 
para entrar en la institución ${ }^{36}$. Con esta medida queda plenamente reflejada la función del hospital como instrumento de estabilidad social, mencionada con anterioridad, y que comienza a manifestarse a finales del siglo XV.

El ayuntamiento era, en el siglo XVI, el encargado del mantenimiento de la fábrica y servicios del hospital ${ }^{37} \mathrm{y}$, por medio de un delegado, recaudaba limosnas para el mismo ${ }^{38}$.

El citado hospital de los Ángeles estaba próximo al convento de Santo Domingo, extramuros de la ciudad, siendo destruido durante el asedio de Drake a la ciudad en el año 1589. En la demarcación que tras este suceso se hace del convento se Santo Domingo se dice:

«a la trasera del cuerpo del altar mayor, por donde [el e]nemigo hizo dos minas contra las murallas de esta ciudad, corral y [hu]erta asta topar en el hospital de los Angeles; y a lo longo de la yglesia de los ángeles, que era capilla de los mareantes de esta ciudad» ${ }^{39}$.

Conforme a los datos aportados, en la Coruña medieval existían varios hospitales, dedicados fundamentalmente a la asistencia de los pobres y peregrinos, el hospital de Santiago y el de los Ángeles. Dependientes de la iglesia y del concejo, contarían con un mínimo de personal médico como pone de manifiesto la presencia de «Martin Sanches, fisiquo» y «Pero Martis, barbeiro» como testigos en un acta municipal del año $1440^{40}$.

La fábrica de los ambos hospitales no debía ser importante, si bien la documentación indica que el hospital de los Ángeles fue construido $e x$

${ }^{36}$ VELO PENSADO, op. cit., p. 335.

${ }^{37}$ En 1564 se abonan a «Lopo Trigo y Galván, carpinterios, diez y seis reales y medio, que hubieron de haber por razón de seis jornales, que por orden de la dicha ciudad trabaxaron en reparar el hospital de los Anxos, para en él recoger los pobres de dicha ciudad e por causa de la mucha hambre que en ella habí». VELO PENSADO, op. cit., p. 335, nota $\mathrm{n}^{\circ} 211$.

${ }^{38}$ SAAVEDRA VÁZQUEZ, María del Carmen: La Coruña durante el Reinado de Felipe II. La Coruña, 1989, p. 78.

${ }^{39}$ Libro de becerro de Santo Domingo de La Coruña, fol. 1 r. Véase referencia completa a documento en nota $\mathrm{n}^{\circ} 127$.

${ }^{40}$ Documento firmado en La Coruña a 31 de mayo de 1440. Transcrito en GONZÁLEZ GARCÉS, op. cit., documento ${ }^{\circ} 64$.

"CUADERNOS DE ESTUDIOS GALLEGOS", Tomo XLIII, Fascículo 108, Santiago 1996. 
novo entre los años 1464 y 1493. Como en el caso de otros hospitales gallegos ${ }^{41}$, todo parece indicar que, al menos el hospital de Santiago, estuviese instalado en casas particulares, en las que se distribuirían los dormitorios y las dependencias accesorias.

Los medios de los hospitales eran escasos y procedían fundamentalmente de la caridad de las gentes. Está es la situación que transmite un documento del año 1502 por el que se solicita de los Reyes Católicos permiso para edificar un hospital ya que todos los que había en la ciudad no eran suficientes para dar asistencia a la ciudad, sobre todo teniendo en cuenta la afluencia de peregrinos a la misma:

«Pedro Moutoto, vecino e regidor de la dicha çibdad, e en nombre della, nos fiso relacion por su petiçion diso que como la dicha çibdad es puerto de mar de continuo vienen a ella muchos romeros de Santiago a buscar pasaje para Flandes e Françia e para otras muchas partes, e que muchas veses an en la dicha çibdad mas de mill romeros pobres, e que en esa dicha çibdad ay quatro espitales que no tienen de renta todos quatro tres mill maravedis de renta. De manera que dis que no tienen ni pueden tener camas ni otra cosa alguna de las que seran nesçesarias, de manera que dis que los romeros andan por las calles e no tienen donde acoger e que sy en la dicha çibdad ay vente capellanias (...) ciertos vesinos desa çibdad e les lexaron sus bienes para la dichas capellanias (...) suplico e pidio por merçed mandasemos que los dichos quatro ospitales se fisiesen uno, e en el se convertiese dicha renta sobredicha de las dichas capellanias» ${ }^{42}$.

Acaso convenga recordar que en estos momentos ha comenzado la edificación del Hospital Real de Santiago; parecía lícito que La Coruña solicitase de los monarcas una concesión parecida.

${ }^{41}$ En su estudio sobre las peregrinaciones en Galicia Vázquez de Parga, Uria Riu y Lacarra destacan varias fundaciones de este tipo en la ciudad de Santiago. VÁZQUEZ DE PARGA, op. cit., T. II., p. 364.

${ }^{42}$ Documento dado en Sevilla a 20 de febrero de 1502. Documento en AGS, sello II1502, fol. 198 .

"CUADERNOS DE ESTUDIOS GALLEGOS", Tomo XLIII, Fascículo 108, Santiago 1996. 
Con la fundación del Hospital Real del hospital real de Santiago ${ }^{43}$ y de Granada $^{44}$, las instituciones hospitalarias comenzarán a abandonar su concepción medieval, como hospedaje y asilo, para convertirse en centros de salud dotados de una infraestructura y personal sanitario adecuados.

Como ya se indicó, dentro de este apartado ha de hacerse una mención aparte al hospital de San Andrés por varias razones: los datos documentales no permiten precisar la fundación; porque frente a los ejemplos anteriormente mencionados se cuenta con documentación gráfica en la que basar su estudio arquitectónico y artístico y, finalmente, porque su erección dependerá de la cofradía de los mareantes de la ciudad.

Con respecto a su fundación ha de indicarse que el hospital de San Andrés no aparece mencionado en ninguna manda testamentaria de las conocidas hasta ahora para la Coruña bajomedieval. Sin embargo, esto no indica de manera rotunda que el hospital no estuviese fundado en el siglo XV. El hecho de que en el informe sobre los hospitales de la ciudad, realizado en el año 1502, se mencione «que en esa dicha çibdad ay quatro espitales» lleva a pensar que en este momento existe un cuarto hospital, que se habría de unir a los de Santa Lucía, Santiago y los Ángeles y cuya presencia no aparece documentada más que en esta breve alusión. A estas circunstancias cabría añadir el hecho de que la mayoría de la documentación conservada en el archivo de dicha institución se pierde en el incendio que tuvo lugar en el edificio en el año 1589.

Acaso por esto cobre valor inestimable la mención que sobre el hospital de San Andrés se recoge en el testamento Martín Sánchez das Mariñas, quien le concede un legado de unas fincas en el año $1515^{45}$. La capacidad

${ }^{43}$ Para ampliar el tema consúltense los trabajos sobre el hospital Real de Santiago de: AZCARATE RISTORI, José María de: «El Hospital Real de Santiago» en Compostellanum. Tomo , Santiago de Compostela, 1965, pp. 863-878; LUCAS ÁLVAREZ, Manuel: El hospital Real de Santiago (1499-1531). Universidad de Santiago de Compostela, Santiago de Compostela, 1964; VILLA-AMIL Y CASTRO, José: «Reseña histórica de los establecimientos de beneficencia que hubo en Galicia durante la Edad Media y de la erección del Hospital Real de Santiago fundado por los Reyes Católicos» en Galicia Histórica. 4(1902) pp. 227-250, 289-312, 353-397; 7(1903) pp. 449-480, 775-783. 8(1903) pp. 513-546, 577-606; 10(1903) pp. 625-637 (para nota véanse pp. 625-637).

${ }^{44}$ Véase el estudio de FELEZ LUBELZA, Concepción: El hospital Real de Granada. Granada, 1979.

${ }^{45}$ VILLA-AMIL Y CASTRO, op. cit., p. 366.

"CUADERNOS DE ESTUDIOS GALLEGOS", Tomo XLIII, Fascículo 108, Santiago 1996. 
del hospital era importante ya que consta que en el año 1588 se asistieron en el a más de quinientos heridos y enfermos de la Armada Invencible ${ }^{46}$. Un año después el hospital es incendiado durante el asedio de Drake a La Coruña, tras este acontecimiento varios vecinos testificarán sobre los servicios prestados durante el asedio, pudiéndose leer en algunas de estas declaraciones las primeras descripciones de dicho hospital y de su iglesia:

«...abia una casa grande, con su patio de pilares, así alto como bajo, con muchos aposentos y camas, echos con efecto, para recojer los enfermos que venían a dicha ciudad y se nombraba del Hospital del señor Santo andrés, que tenía ciento ciencuenta camas, con su ropa blanca y lo más necesario para el servicio de los enfermos, que en el se curaban y se recogían muchos peregrinos extrangeros y los pobres de la tierra» ${ }^{47}$

«que el dicho hospital tenida una (iglesia) que era una de las parroquias de la dich a cibdad de muy buen edificio y con muy lindo retablo dorado e grande y con muchas imagenes y altares y con muchos ornamentos de seda guarnecidos de brocado y de otras suertes con sus cálices y patenas de plata con todo lo demás necesario que se requiere para el servicio del culto divino» ${ }^{48}$.

Un año después un temporal contribuirá arrasar lo poco que del hospital quedaba en pie ${ }^{49}$, comenzando las reparaciones en el año 1592 según consta en la visita realizada por Thomas Strong, obispo de Ossory (Irlanda), por delegación del arzobispo Juan San Clemente, entre los días 4 y 29 de abril de dicho año:

\footnotetext{
${ }^{46}$ MARTÍNEZ SALAZAR, Andrés: «De mareantes. Los dos reales por la pesca del congrio» en Algunos temas gallegos. T. II, La Coruña, 1981, pp. 319-330 (para nota p. 321).

${ }^{47}$ Documento transcrito en su integridad en MARTíNEZ SALAZAR, Andrés: El cerco de La Coruña en 1589 y Mayor Fernández Pita. (Colección: Biblioteca Gallega) Edición facsímil, Ed. División de artes gráficas de «La Voz de Galicia» S.A., La Coruña, 1988 , documento $\mathrm{n}^{\circ} 25$.

${ }^{48}$ IDEM, p. 25.

${ }^{49}$ PARRILLA HERMIDA, op. cit., p. 98.
}

"CUADERNOS DE ESTUDIOS GALLEGOS", Tomo XLIII, Fascículo 108, Santiago 1996. 
«que el dicho hospital y cofradía al presente no tiene sino los hornamentos que se siguen; porque los demas que tenida, se avian perdido y quemado en el rebato y guerra de los enemigos que ubo en el año de ochenta y nuebe en donde se quemo todo el dicho hospital con su iglesia y capilla que al presente se comienza a reparar» ${ }^{50}$.

Las vicisitudes posteriores del inmueble y su patente abandono que comenzará en los siglo XVII y XVIII ${ }^{51}$, llevará a que, en junio de 1879 , el ayuntamiento de la ciudad obligue a sus propietarios a cerrar la capilla al culto $^{52}$.

La iglesia fue construida de nuevo a partir de 1890, en estilo neogótico, siguiendo las pautas de por Faustino Domínguez y gracias al mecenazgo de Eusebio da Guarda ${ }^{53}$.

No se puede conjeturar mucho acerca del aspecto que este hospital debía presentar. Por la descripción de 1589 donde se dice «...abia una casa grande con su patio de pilares, así alto como bajo, con muchos aposentos y camas, echos con efecto» ${ }^{54}$, el edificio parece responder a la tipología hospitalaria desarrollada en los siglos medievales paralelamente a las fundaciones en casas particulares. Este modelo es definido por Adell ${ }^{55}$ como un hospital concebido como un volumen compacto, de planta cua-

\footnotetext{
${ }^{50}$ Testimonio de la visita incluido en el pleito entre el hospital y cofradía de San Andrés con Juan Andrés y consortes. Año 1772. Documento en ARG, pleitos de hospitales, leg. 24730, documento ${ }^{\circ} 27$.

${ }^{51}$ «En tiempos del arzobispo de Santiago D. Rodrigo de Monroy, en la que dice de aquel edificio: «visitó la iglesia de San Andrés que está en términos de la parroquia de san Nicolás y hallase arruinada desde su medio cuerpo hasta su puerta por haberse hundido el techo: mando SS que el capellán del hospital que ahi reside, a cuyo cargo está el decir misa en dicha iglesia en interin que se cubre y redifique dicha iglesia, cuando sucede haber aires recios o tempestadas en que pueda tenerse algún género el riesgo en otra parte; y en la dicha iglesia procure que las imágenes que están o hubieran en las dos colaterales no se les maltrate, antes se recojan en parte decente». REY ESCARIZ, op. cit., p. 173.

${ }^{52}$ IDEM, p. 174.

${ }^{53}$ BARREIRO FERNÁNDEZ, op. cit., p. 290.

${ }^{54}$ Véase referencia completa al documento en nota $\mathrm{n}^{\circ} 48$

${ }^{55}$ ADELL I GISBERT, Johan-Albert: «L'Hospital de pobres de Santa Magdalena de Montblanc i l'arquitectura hospitalària medieval a Catalunya» en Acta historica et archaeologica mediaevalia. 4 (1983), pp. 239-163 (para nota pp. 243-244).
}

"CUADERNOS DE ESTUDIOS GALLEGOS", Tomo XLIII, Fascículo 108, Santiago 1996. 
drada o rectangular, en el que se destaca un pequeño patio interior porticado, alrededor del cual, y normalmente organizadas en dos pisos, se distribuirían las diferentes estancias.

El conjunto hospitalario de San Andrés aparecía constituido por una «iglesia y con sus aposentos y enfermeria ${ }^{56}$. Dentro del plano que sobre la ciudad realiza Juan Santáns y Tapia, en el año 1639, se distingue una plaza delante del Orzán entre cuyas edificaciones se puede identificar un crucero y una iglesia con torre. Aunque los detalles aportados por este plano no permiten afirmar que la iglesia estuviese incluida dentro del mismo recinto hospitalario, como una dependencia anexa y no independiente del mismo, lo cierto es que todo apunta a confirmar esta idea ya que el único plano conservado del templo, datado en 1768 y depositado en el Archivo Histórico Nacional ${ }^{57}$ (Ilustración I), el que aparezca la casa del sacristán y las dependencias de la cofradía comunicadas directamente con los pies de la iglesia, parece demostrar que la iglesia comunicaba directamente con el antiguo recinto hospitalario, antes de la desaparición del mismo, el plano muestra una iglesia de una sola planta con ábside cuadrado, más estrecho que la nave, y con una tribuna a los pies. Poco

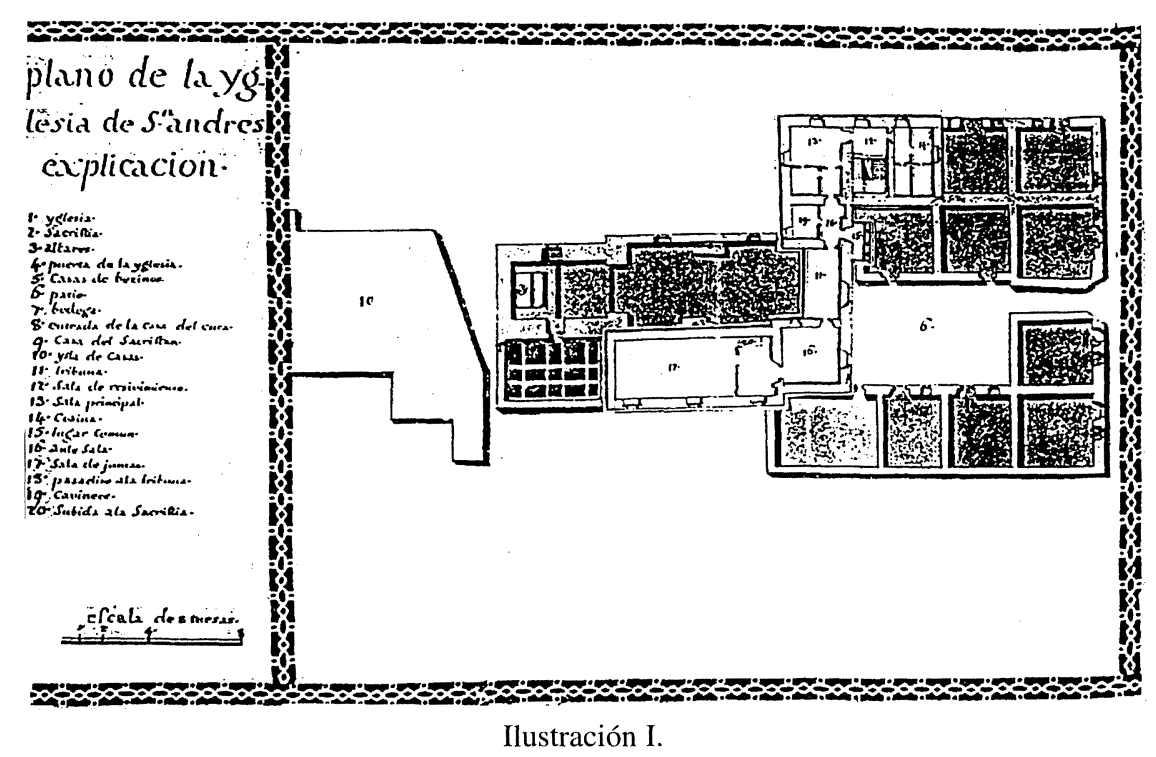

${ }^{56}$ ARG, pleitos de hospitales, leg. 17297, $\mathrm{n}^{\circ} 57$.

${ }^{57}$ AHN, sección consejo, legajo 281 documento $\mathrm{n}^{\circ} 9$, plano $\mathrm{n}^{\circ} 868$.

"CUADERNOS DE ESTUDIOS GALLEGOS", Tomo XLIII, Fascículo 108, Santiago 1996. 
más podría mencionarse sobre la citada iglesia de no ser por los restos conservados de la misma y de los detalles que sobre ésta transmiten Bernardo de Barreiro y Antonio de la Iglesia cuando aún no se había derribado. Con respecto al exterior de la misma, Bernardo de Barreiro describe «el ábside con sus ventanitas de peraltados y festoneados arcos, lumbreras de color que por todas partes iluminaban el tabernáculo, hubo de taparse con un mal agregado de sacristía ${ }^{58}$ y el alero de la iglesia presentaba canecillos de «figuras caprichosas» ${ }^{59}$.

Por su parte, Antonio de la Iglesia añade: «otra de las antigüedades era el muy notable aunque tosco bajo relieve de incorrectas proporciones que se conservaba incrustado exteriormente en lo alto de la antigua pared meridional, representando el martirio de la Cruz de San Andrés confortado con el Viático que un ángel baja a suministrarle, alentado igualmente con la presencia de la Santísima Virgen. Esta primitiva pieza de granito, aparte de la expresiva piedad y sentimiento que revela, era el más fehaciente testimonio de la antigüedad remota del santuario ${ }^{60}$. Como complemento habrá de indicarse que este mismo autor describe los enterramientos aparecidos en el interior de la iglesia:

"Se hallan los que con motivo de la reedificación de la capilla de San Andrés de La Coruña se descubrieron en las sepulturas del interior de la iglesia. Una de ellas, hacia el altar, primero colateral del evangelio, que era de la Virgen de los Dolores, se halló cubierta con una lápida con inscripción en relieve, de caracteres góticos y románicos entremezclados, y abajo de la inscripción un cáliz asimismo esculpido, entre dos grandes llaves de empuñadura trifolia. En medio de las diversas guardas y fuera de sus bordes, se percibian, en cada llave, otras tres de aquellas que eran oquedades ó taladros en forma de cruces griegas. Un ramo de palmera partía desde el centro de la base ó lado corto inferior de esta cara de la lápida, hasta encontrar el pie del cáliz sobredicho, toda la escultura, de relieve que aún se conservaba alto a pesar de lo gastado por el uso, hallándose como se halla-

\footnotetext{
${ }^{58}$ BARREIRO DE VÁZQUEZ VARELA, Bernardo: «La capilla de San Andrés y su instituto da Guarda» en Galicia Diplomática. 3(1888) pp. 261-264 (para nota p. 261).

${ }^{59}$ IDEM, p. 262.

${ }^{60}$ IGLESIA GONZÁLEZ, Antonio de la: «San Andrés de La Coruña» en Galicia Diplomática. 3(1888), pp. 169-170 (para nota p. 170).
}

"CUADERNOS DE ESTUDIOS GALLEGOS", Tomo XLIII, Fascículo 108, Santiago 1996. 
ba la lápida formando parte del pavimento. La inscripción, en gallego; breve, únicamente de cuatro palabras, y para eso, en cada palabra una abreviatura. Su dibujo tan curioso que la inscripción por si sola merecía un grabado. su última letra una cedilla

\section{$A Q I I Z$ \\ STIA \\ GO GZ}

Es decir: Aquí jaz Santiago gonzález (...) Apareció también otra lápida sepulcral con relieve, representando el hacha del oficio de carpintero» ${ }^{61}$.

En la actualidad se conservan pocos restos de la iglesia: una pila bautismal de granito (actualmente en el Museo Arqueológico Provincial) con una decoración muy imprecisa por el deterioro pero que, acaso, parezca perfilar una venera y motivos de decoración vegetal: todo muy difícil de precisar lo que impide su atribución cronológica (Ilustración II). Sin duda la portada de acceso al antiguo complejo hospitalario es la pieza más interesante a la que curiosamente no se ha dado el estudio que le corresponde y que se ha conservado gracias a la declaración de la misma como monumento histórico artístico, evitando con ello el intento de demoler de la misma junto con la iglesia ${ }^{62}$. Dicha portada fue colocada, en el año 1956, en la muralla de la ciudad a la altura de jardín de San Carlos (Ilustración III).

${ }^{61}$ DE LA IGLESIA, op. cit., pp. 169-170.

${ }^{62}$ «La comisión de monumentos de la Coruña, consideró dicho arco como monumento artístico-histórico muy interesante para la ciudad, y digno de conservarse, por cuyos motivos le incluyó en el catálogo de esta clase de monumentos de la provincia que formó en 16 de enero de 1880 y elevó á la Superioridad para su aprobación (...) habiéndose quitado el tejadillo que cubría el arco al derribar la capilla de San Andrés, la comisión Provincial de monumentos nombró una comisión de su seno en 16 de mayo de 1882, para que gestionase la restitución del arco al ser y estado que se hallaba en mayo de 1881 (...) en 10 de octubre de 1883, emitió de nuevo su dictamen una Subcomisión de la provincial de monumentos incluyendo en el una fotografía del arco y el informe de la comisión de la policía urbana, en que ésta manifestaba la necesidad de demoler el mencionado arco por su estado ruinoso y por ser necesaria esta medida para ensanche de la vía pública y mejora de la población». RUIZ DE SALCES, Antonio: «Pórtico de San Andrés (La Coruña)» en Boletín de la Real Academia de Bellas Artes de San Fernando. Primera época, 4 (1886), pp. 80-84.

"CUADERNOS DE ESTUDIOS GALLEGOS", Tomo XLIII, Fascículo 108, Santiago 1996. 


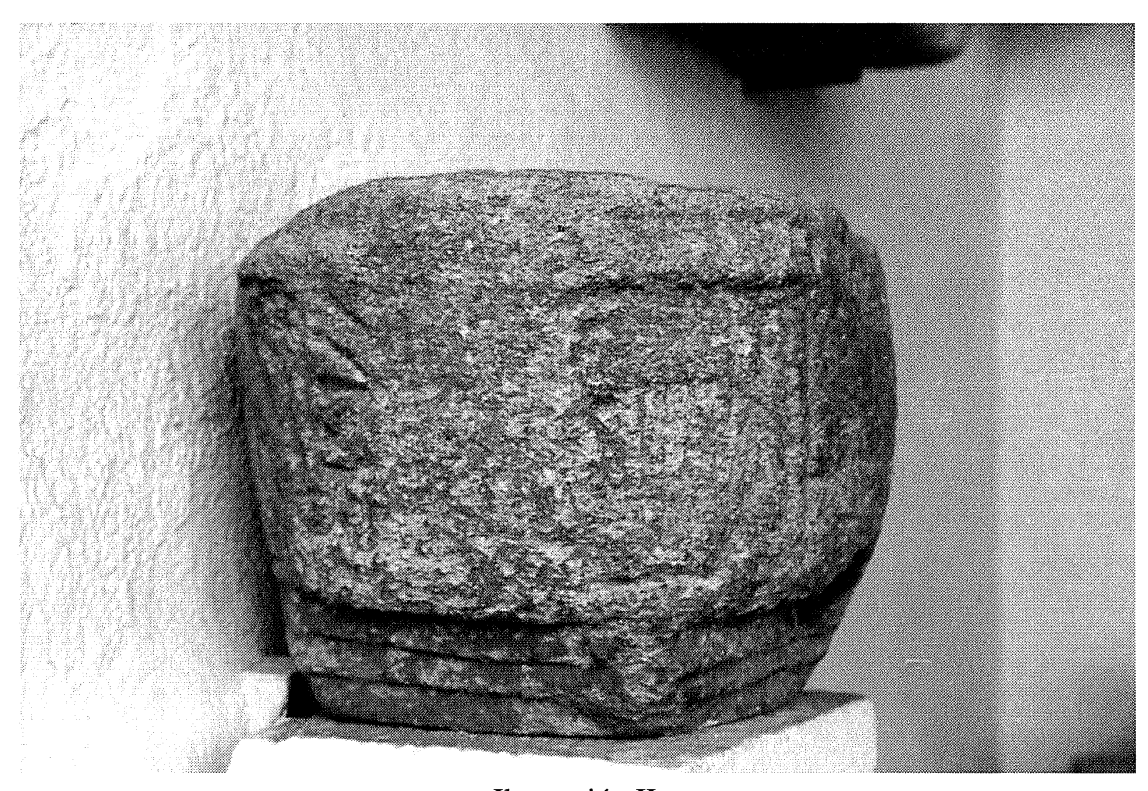

Ilustración II.

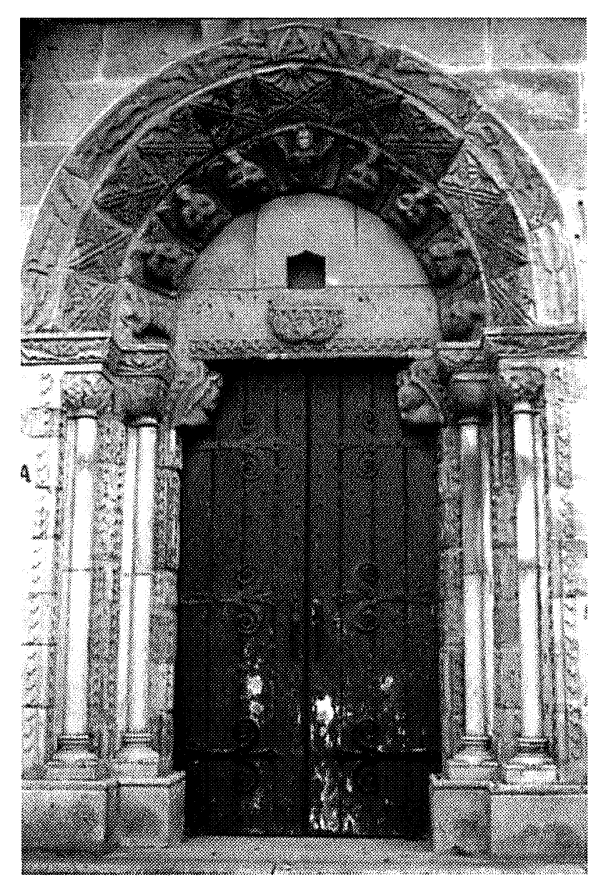

Ilustración III. 
Esta portada, calificada por González Garcés de tardorrománica ${ }^{63}$ y por Castillo como perteneciente al siglo $\mathrm{XIV}^{64}$, ha de ser atribuida, teniendo en cuenta los datos documentales aportados, a fines del siglo $\mathrm{XV}$ comienzos del siglo XVI, pero sin poder precisar con exactitud su cronología, ya que si bien ciertos rasgos generales de construcción parecen indicar una pertenencia total al gótico pleno gallego, determinados motivos decorativos e iconográficos acercan su cronología a los momentos finales del estilo.

La fachada aparece conformada por una portada de arco ligeramente apuntado, formada por tres arquivoltas que descansan en una línea de imposta decorada con el motivo de hojas de cardo, que a su vez se apoya en otros dos pares de columnas acodilladas por lado coincidiendo con las arquivoltas interiores. Estas columnas presentan capiteles con decoración vegetal -los fustes, basas y el capitel exterior del lado izquierdo son de nueva factura- destacándose los intercolumnios y jambas de la puerta profusamente decorados con motivos vegetales muy geometrizados. Completa la portada un tímpano que descansa en sendos ángeles, en cuyo centro liso se ubica a una peana decorada con motivos vegetales.

La arquivolta exterior de la portada aparece exornada con el motivo decorativo de peces, alusivo sin duda a la cofradía titular de la iglesia. La segunda presenta una decoración vegetal estilizada constituida por hojas que se unen en forma de aspa, no ha de olvidarse que precisamente es la cruz aspada es el símbolo del Santo patrón del templo. La arquivolta interior aparece decorada por ocho figuras que rodean a la figura del Salvador. Siete ángeles con alas explayadas en actitud de oración y de rodillas, y un octavo ángel, que ocupa el extremo inferior izquierdo de la arquivolta, diferente a los demás tanto en factura como en su composición ya que porta una cartela. Los siete ángeles anteriormente mencionados aparecen ataviados con vestiduras eclesiásticas que se dejan intuir a través de la presencia del cíngulo que ciñe los ropajes y que en algunas figuras remata en forma de cordón anudado.

${ }^{63}$ GONZÁLEZ GARCÉS, op. cit., p. 417.

${ }^{64}$ CASTILLO LÓPEZ, Ángel del: «La arquitectura en Galicia» en Geografía general del Reino de Galicia. (Dir. Carreras Candi) Tomo II. Ediciones Gallegas S.A., La Coruña 1980, p. 831-1104 (para nota p. 1046).

"CUADERNOS DE ESTUDIOS GALLEGOS", Tomo XLIII, Fascículo 108, Santiago 1996. 
La presencia de este cordón pondría al hospital en relación directa con los franciscanos coruñeses, con la idea que vinculaba directamente a la Orden con la participación en el mundo celestial a través de aquellos que hicieran uso de su hábito penitencial como pasaporte para el más allá6s, además de la familiaridad de esta orden con la atención al necesitado, tal como había establecido su fundador:

«deben gozarse (los frailes) cuando conviven con gente de baja condición y despreciada, con los pobres y débiles, y con los enfermos y leprosos, y con los mendigos de los caminos»

(Regla Primera, capitulo IX, 2) ${ }^{66}$

Esta hipótesis parece muy en consonancia con la teoría de Rey Escariz, quien vinculaba esta Orden con las fundaciones hospitalarias de los mareantes coruñeses ${ }^{67}$. Acaso para resaltar esta idea convenga mencionar el contenido de un documento de fines del siglo XVI, donde se especifica que la cofradía de San Andrés contrata con el convento de San Francisco la asistencia religiosa en dicho hospital ${ }^{68}$.

La figura del Salvador ocupa el centro de la arquivolta interna y aparece representado semidesnudo, con melenas, imberbe, con un manto sobre los hombros que sale por debajo de sus brazos, los cuales aparecen explayados en actitud de mostrar las llagas, y en el que se remarca la anatomía de su torso (Ilustración IV). En lo que se refiere a esta figura cabe destacar su tratamiento anatómico «topográfico» y el respeto al principio de la proporción; es decir, minucioso en sus detalles y lejos de las viejas concepciones anatómicas galénicas que habían primado hasta los

${ }^{65}$ A este respecto véase el caso del estudio que sobre el valor del hábito franciscano realiza: NÚÑEZ RODRÍGUEZ, Manuel: «La indumentaria como símbolo en la iconografía funeraria» en Fragmentos. Revista de Arte. 10(1987), pp. 73-84.

${ }^{66}$ Texto tomado de GUERRA, José Antonio (ed.): San Francisco de Asís. Escritos. Biografías. Documentos de época. (Colección: Biblioteca de Autores Católicos No 399), la editorial Católica, Madrid, 1985, p. 98.

${ }^{67}$ REY ESCARIZ, op. cit., p. 171

${ }^{68}$ RODRÍGUEZ PAZOS, Manuel: «Cofradías piadosas y capellanías castrenses en el convento de San Francisco de La Coruña (Siglos XVI-XVII)» en BRAG 24 (1944), pp. 423-437 (para nota pp. 428-430).

"CUADERNOS DE ESTUDIOS GALLEGOS", Tomo XLIII, Fascículo 108, Santiago 1996. 


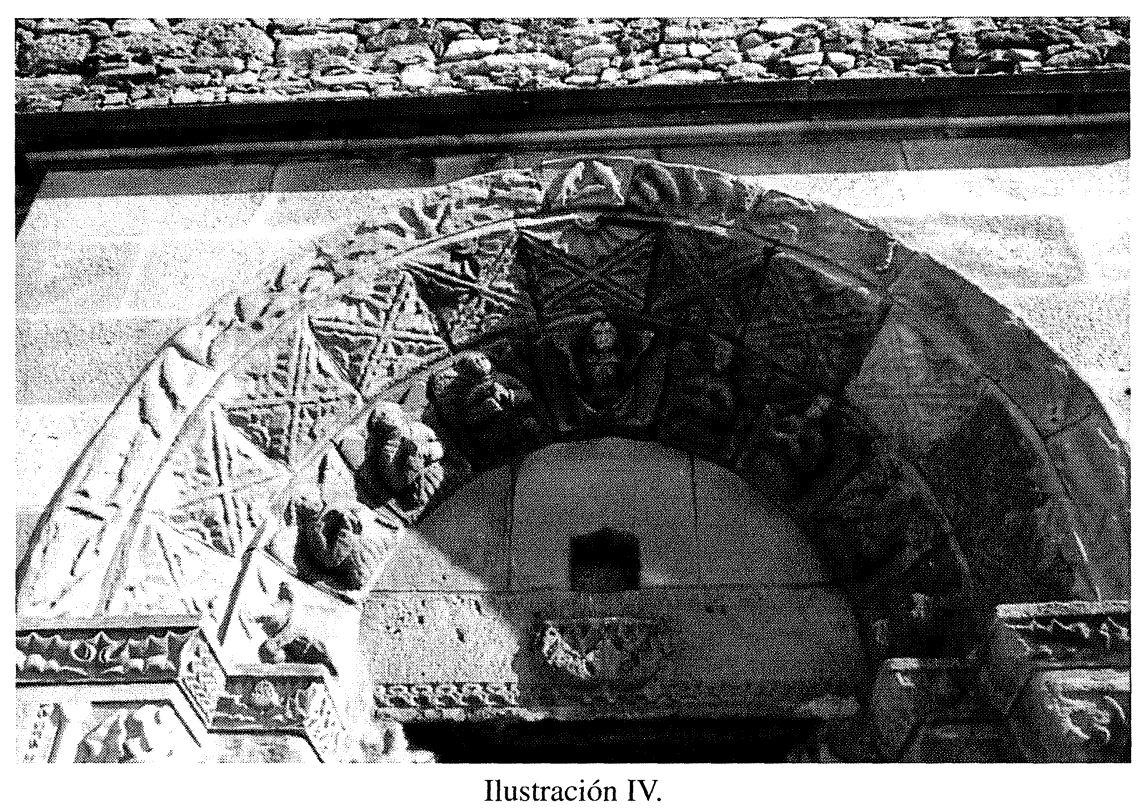

años finales del siglo $\mathrm{XV}^{69}$. Si se establece una comparación entre esta imagen y la gótica conservada en la clave de la fachada principal de la iglesia parroquial de Santiago de La Coruña (Ilustración V) esta segurida todavía se adhiere a la idea de las viejas disecciones galénicas amparadas en la forma de abordar los conocimientos anatómicos a partir del análisis por disección de animales y, sobre todo, trae al recuerdo aquellas disecciones del tórax de un cadáver que los libros de práctica médica comenzaron a divulgar a partir de los años centrales del siglo XIV. Así por ejemplo el Liber Notabilium de Guido de Pavia ${ }^{70}$.

La imagen de Cristo mostrando las llagas de la clave de este hospital ofrece, por el contrario, un conocimiento anatómico más elaborado y,

${ }^{69} \mathrm{El}$ análisis de las prácticas anatómicas y su vinculación con el mundo del arte ha sido realizado siguiendo las directrices de un curso de doctorado impartido por el catedrático de historia del arte Dr. D. Manuel Núñez Rodríguez, quien ha compartido sus investigaciones con la autora analizando la filiación de dicha portada.

${ }^{70}$ Sobre los progresos de la cirugía y sus tratadistas véase BEUJOUAN, Guy: «La medicina a fines de la Edad Media» en Historia general de las ciencias. T. III. Barcelona, 1988, pp. 690-696 (para nota p. 691-694).

"CUADERNOS DE ESTUDIOS GALLEGOS", Tomo XLIII, Fascículo 108, Santiago 1996. 


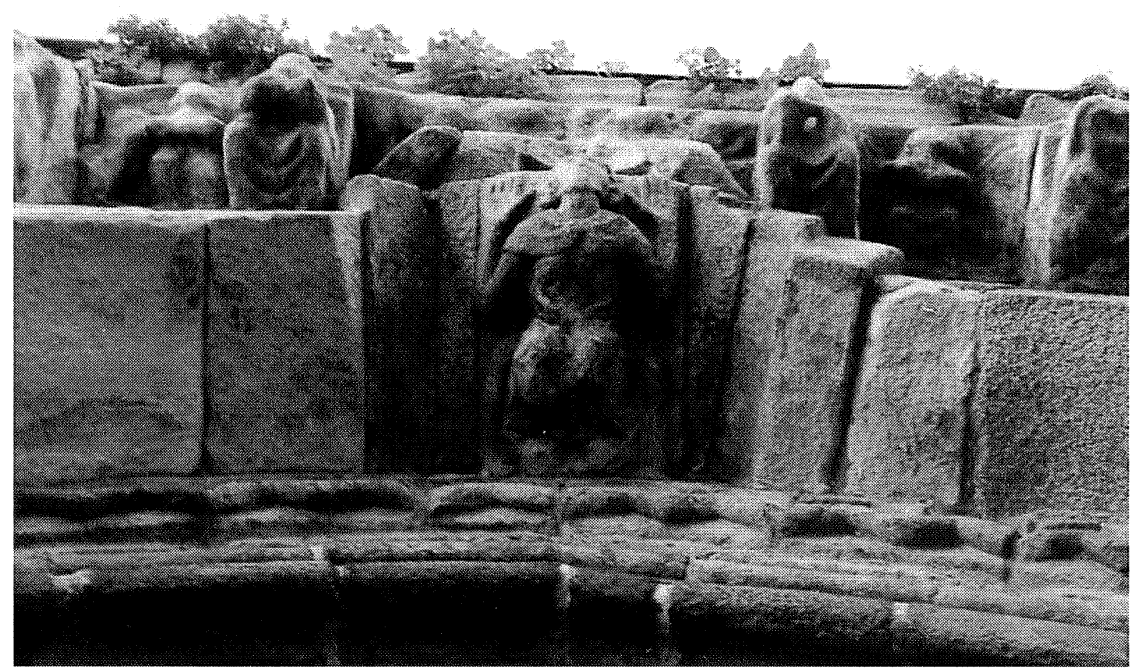

Ilustración V.

sobre todo, un mejor análisis de la estructura del cuerpo humano como lo demuestran los propios huesos de las caderas. Esto llevaría a la figura hacia el siglo XVI, cuando los estudios de anatomía experimentados por Vesalio o Ambrosio Paré dejan atrás los obsoletos esquemas de Galeno. En un momento en que el campo de batalla se convierte en un espacio idóneo para que el cirujano adquiera práctica y conocimiento con el cuerpo del soldado herido o muerto. Pero tampoco ha de olvidarse que éste es un tiempo en que entra en juego una mayor atención a la política sanitaria y en el que la Iglesia no obstaculiza, como en el pasado, la práctica quirúrgica.

"CUADERNOS DE ESTUdIOS GALLEGOS", Tomo XLIII, Fascículo 108, Santiago 1996. 